\title{
FLUTUAC̣ÃO POPULACIONAL DE ESPÉCIES DE CHRYSOMYA ROBINEAU-DESVOIDY (DIPTERA, CALLIPHORIDAE) EM POMAR DE GOIÂNIA, GOIÁS, BRASIL
}

\author{
Maria Judy de Mello Ferreira ${ }^{1}$ \\ Benedito Baptista dos Santos ${ }^{1}$ \\ Hélida Ferreira da Cunha 1,2
}

\begin{abstract}
PopUlation fluctuation of Chrysomya Robineau-Desvoidy (Diptera, Calliphoridae) speties in orchard from Goiannia, Golás. Brazil. Three species of Chrysomya were collected and the most frequent were: C. albiceps (Wiedemann, 1819) (62.62\%), C: putoria (Wiedeman, 1818) (30.11\%) and $C$. megacephala (Fabricius, 1794) $(7.27 \%)$. The peaks of the populations of these species occurred in November and December/1988 and October and November/1989. and the small frequencies occurred from April to June/1989. All species showed significant correlation to $5 \%$ level with pluviometric precipitation. and none species showed correlation with temperature and relative humidity.

KEY WORDS. Diptera, Calliphoridae, Chrysomya, orchard
\end{abstract}

Com o objetivo de se conhecer as espécies de insetos associadas às frutíferas realizou-se no período de 1988-1989, um levantamento em pomares diversificados em Goiânia (Goiás), da Chácara São Domingos e da Escola de Agronomia da Universidade Federal de Goiás. Dentre os diversos grupos de insetos que ocorreram neste período destacaram-se, sobremaneira, os califorídeos do gênero Chrysomya Robineau-Desvoidy, 1830. Considerando-se o fato de já terem sido realizados estudos em Goiânia sohre o comportamento das espécies de Chrysomya (FERREIRA 1985; FERREIRA \& LACERDA 1993) estudou-se, no presente trabalho, a flutuação populacional das espécies, correlacionando-as com alguns parâmetros ambientais. Estas moscas, juntamente com outros califorídeos, sarcofagídeos, muscídeos e faniídeos, constituem um grupo de insetos extremamente importante, cujo fenômeno de sinantropia é bem definido. Isto se dá porque suas larvas se desenvolvem em substratos que estão associados ao homem em seu processo de urbanização, tais como excrementos, carcaças de animais, lixos urbanos, etc. (FERREIRA 1985).

As espécies de Chrysomya foram introduzidas no Brasil a partir da década de 70 (IMBIRIBA et al. 1977; GuIMARÃEs et al. 1978), e desde então, têm se dispersado amplamente (Guimarães et al. 1979; Prado \& Guimarães 1982; FERREIRA 1985). Sua importância do ponto de vista ecológico, médico-sanitário

1) Departamento de Biologia Geral, Instituto de Ciências Biológicas. Universidade Federal de Goiás. Caixa Postal 131, 74001-970 Goiânia, Goiás. Brasil.

2) Bolsista do CNPq. 
e econômico, tem sido demonstrada por diversos pesquisadores. GREenBERG (1988) considera que Chrysomya putoria (Wiedemann, 1818) e Chrysomya megacephala (Fabricius, 1794), no Novo Mundo, podem ser mais nocivas para o homem que Musca domestica Linnaeus, $1758 \mathrm{em}$ locais sem saneamento. GREENBERG (1971) e HERZ()g et al. (1989) se referem ainda, à capacidade de veiculação de hacterioses, viroses, polioviroses e enterites graves por moscas do gênero Chrysomya.

\section{MATERIAL E MÉTODOS}

As coletas foram semanais de novembro de 1988 a novembro de 1989 , utilizando-se como armadilhas o frasco caça-mosca adaptado pela Escola de Agronomia da Universidade Federal de Goiás (Veloso et al. 1994). Neste trabalho considerou-se apenas os dados referentes à Chácara São Domingos. As armadilhas, em número de 10, foram distribuídas ao acaso e instaladas à $1,80 \mathrm{~m}$ de altura, no interior das copas das árvores. O substrato atrativo utilizado foi suco de laranja à $50 \%$ e açúcar a $10 \%$ na quantidade de $200 \mathrm{ml}$ por frasco, trocado semanalmente. Os insetos após retirados das armadilhas foram colocados em álcool a 70\%. No laboratório procedeu-se à triagem, identificação, quantificação e montagem de alguns exemplares que estão depositados na Coleção do Museu de Entomologia, Departamento de Biologia Geral, Universidade Federal de Goiás.

Apesar das coletas terem sido realizadas semanalmente, os valores aqui apresentados foram expressos em número total de moscas/mês e correlacionados com temperatura, precipitação pluviométrica e umidade relativa do ar fornecidos pela Estação Meteorológica, Universidade Federal de Goiás. As freqüências das populações das três espécies foram correlacionadas com os dados meteorológicos, através do pacote estatístico SAEG, utilizando-se a metodologia de Regressão Múltipla Step Wise, ao nível de $5 \%$ de probabilidade.

\section{LOCAL DA COLETA}

A Chácara São Domingos situa-se acerca de $20 \mathrm{Km}$ à noroeste do centro da cidade de Goiânia. O pomar diversificado é constituído por cerca de 400 árvores e composto principalmente por citros, além de outras frutíferas como: cajamanga, carambola, jahoticaba, goiaba, manga, figo, pêssego, ahacate. Próximo a este local encontram-se instalados frigoríficos, curtumes e laticínios, além de edificações e conjuntos habitacionais.

\section{RESULTADOS}

Foram coletadas 31.254 moscas do gênero Chrysomya, sendo $62,62 \%$ de C. albiceps (Wiedemann, 1819): 30,11\% de C. putoria e 7,27\% de C. megacephala (Tab. I). Chrysomya albiceps foi sempre a espécie dominante, seguida por C. putoria e C. megacephala. O gênero Phaenicia Robineau-Desvoidy, 1863 , também composto por moscas sinantrópicas, registrado em Goiânia por FERREIRA (1985) e FERREIRA \& LACERDA (1993), ocorreu em número insignificante de indivíduos, menor que dez exemplares em todo o período. 
As três espécies apresentaram seus picos populacionais em novembro e dezembro de 1988, e em outubro e novembro de 1989; e as menores freqüências de ahril a junho de 1989 (Tah. I). Na tabela Il encontram-se os valores médios mensais de temperatura e umidade relativa e os valores totais de precipitação.

A análise estatística realizada entre as freqüências das espécies coletadas e os dados meteorológicos, indicou que no período considerado, a precipitação) pluviométrica influiu significativamente na freqüência de distribuição das populações de $C$. albiceps, $C$. putoria e $C$. megacephala, enquanto que a temperatura e a umidade relativa não tiveram influência significativa para nenhuma das espécies.

Tabela I. Número total e frequeencia relativa (\%) das três espécies de Chrysomya, no período de novembra/88 a novembro/89, no pomar da Chácara São Domingos (Goiânia, Goiás) .

\begin{tabular}{lrrrr}
\hline \multicolumn{1}{c}{ Meses } & C. albiceps & C. putoria & C. megacephala & Total \\
\hline Novembro & 4318 & 2388 & 435 & 7141 \\
Dezembro & 5828 & 2266 & 323 & 8417 \\
Janeiro & 62 & 15 & 9 & 86 \\
Fevereiro & 77 & 39 & 17 & 133 \\
Março & 90 & 54 & 26 & 170 \\
Abril & 14 & 3 & 3 & 20 \\
Maio & 16 & 17 & 5 & 38 \\
Junho & 7 & 9 & 4 & 20 \\
Julho & 343 & 35 & 97 & 475 \\
Agosto & 39 & 30 & 4 & 73 \\
Setembro & 807 & 143 & 104 & 1054 \\
Outubro & 1004 & 744 & 585 & 2333 \\
Novembro & 6966 & 3668 & 660 & 11294 \\
\hline Total & 19571 & 9411 & 2272 & 31254 \\
Porcentagem & 62,62 & 30,11 & 7,27 & 100,00 \\
\hline
\end{tabular}

\section{DISCUSSÃO}

A literatura conhecida se refere sempre à ocorrência de dípteros sinantrópicos em material em decomposição de origem animal, como restos de animais, sobretudo carcaças que constituem o substrato fundamental para o desenvolvimento dos califorídeos (NoRRIS 1965).

No Brasil, tem-se constatado que substrato animal como fezes humanas, vísceras de aves e peixes em decomposição, têm sido excelente isca atrativa para estas moscas (LINHARES 1981; Prado \& GUIMARĀES 1982; FERREIRA 1985; MENDES \& LiNHARES 1993). Contudo, no presente levantamento, constatou-se uma grande ocorrência de Chrysomya em material de origem vegetal (solução de suco de laranja). MENDES \& LINHARES (1993), estudando Chrysomya, utilizaram diversas iscas de origem animal e, também, suco de abacaxi, sem no entanto se referirem ao nível de preferência destas moscas pelo substrato de origem vegetal. 
Tabela II. Valores médios mensais de temperatura $\left({ }^{\circ} \mathrm{C}\right)$, umidade relativa $(\%)$ e valores totais de precipitação pluviométrica $(\mathrm{mm})$ no período de novembro/88 a novembro/89 obtidos da Estação Meteorológica, Universidade Federal de Goiás (Goiânia, Goiás).

\begin{tabular}{lccc}
\hline \multicolumn{1}{c}{ Meses } & Temperatura $\left({ }^{\circ} \mathrm{C}\right)$ & Precipitação $(\mathrm{mm})$ & Umidade Relativa (\%) \\
\hline Novembro & 23,7 & 225,1 & 72,0 \\
Dezembro & 23,3 & 215,3 & 77,0 \\
Janeiro & 23,6 & 175,3 & 75,0 \\
Fevereiro & 23,7 & 160,6 & 75,0 \\
Março & 23,5 & 210,2 & 73,0 \\
Abril & 23,5 & 46,5 & 69,0 \\
Maio & 20,7 & 0,0 & 67,0 \\
Junho & 20,4 & 12,6 & 68,0 \\
Julho & 19,8 & 29,0 & 65,0 \\
Agosto & 22,3 & 60,5 & 77,0 \\
Setembro & 23,5 & 63,4 & 75,0 \\
Outubro & 24,5 & 168,7 & 71,0 \\
Novembro & 23,5 & 418,9 & 80,0 \\
\hline
\end{tabular}

Entretanto, sugerem que as fềmeas das espécies de Chrysomya utilizam iscas como fezes humanas, vísceras de galinha e carcaça de roedores, principalmente para obtenção de nutrientes para o desenvolvimento dos ovaríolos.

A ocorrência das Chrysomya neste pomar (31.254 moscas) que foram atraídas por isca vegetal, poderia também ser explicada pelo fato do pomar se localizar em região que está sofrendo ação antrópica, existindo em seus arredores, frigoríficos, curtumes e laticínios, bem como edificações de conjuntos habitacionais, levando à conseqüente formação de maiores quantidades de lixos e restos associados ao homem. Estes locais são considerados excelentes fontes de criação utilizadas pelos muscóideos sinantrópicos que apresentam grande capacidade de dispersão dos locais de criação para a cidade como já foi constatado por QUARTERMAN et al. (1954) nos E.U.A.. Sugere-se, assim, que devem ser realizados estudos com outros tipos de isca de origem vegetal, bem como estudos comparativos de atratividade entre iscas de origem animal e vegetal.

Provavelmente, devido ao fato de que a chuva é o fator que bem caracteriza o clima da região onde se localiza o município de Goiânia, demarcando inclusive, uma época seca no inverno e outra chuvosa no verão, este influenciou de maneira significativa a distribuição de $C$. albiceps, $C$. putoria e $C$. megacephala no período estudado. Assim, os picos de ocorrência das espécies se deram à partir de outubro até dezembro. LOMÔNACO \& PRADO (1994), estudando a estrutura comunitária da fauna de dípteros em granjas avícolas em Uberlândia (Minas Gerais), constataram que $C$. putoria (segunda espécie mais abundante) apresentou marcante sazonalidade, influenciada pelo fator temperatura. Considerando-se que cada espécie reage de maneira peculiar às condições ambientais e que não só os fatores climáticos interferem na dinâmica das populações destes dípteros, sugere-se que mais estudos sejam realizados, abordando outros fatores, para melhor se entender as interações das Chrysomya com o meio ambiente. 
AGRADECIMENTOS. Aos Professores Valquíria R.S. Veloso da Escola de Agronomia da Universidade Federal de Goiás pelas amostras cedidas e Joaquim C. Sena Maia. Departamento de Estatístiea da Universidade Federal do Paraná, pela colaboração na análise estatística; e ao Dr. Renato R.C. Dutra, Departamento de Zoologia, Universidade Federal do Paraná pela leitura do manuscrito.

\section{REFERÊNCIAS BIBLIOGRÁFICAS}

Ferreira, M.J.M. 1985. Sinantropia de Calliphoridae (Diptera) em Goiânia-GO. Goiânia, Editora Universidade Federal de Goiás, 37: 140p.

FERreira, M.J.M. \& P.V. LACERDA. 1993. Muscóides sinantrópicos associados ao lixo urbano de Goiânia-GO. Revta bras. Zool. 10 (2): 185-195

Greenberg, B. 1971. Flies and Diseases. Princeton, University Press, vol. 1, $856 \mathrm{p}$.

1988. Chrysomya megacephala (F.) (Diptera: Calliphoridae) collected in North America and notes on Chrysomya species present in the New World. J. Med. Ent. 25 (3): 199-200.

GuimarÃEs, J.H.; A.P. PRADO \& A.X. Linhares. 1978. Three newly introduced species of Chrysomya Robineau-Desvoidy in Brazil (Diptera, Calliphoridae). Revta bras. Ent. 22 (1): 53-60.

Guimarães, J.H.; A.P. Prado \& G.M. Buralli. 1979. Dispersal and distribution of three newly introduced species of Chrysomya Robineau-Desvoidy in Brazil (Diptera, Calliphoridae). Revta bras. Ent. 23 (4): 245-255.

HerzoG, J.D.; E.M.V. Milward-De-Azevedo; M.A.S. Freitas \& E.H.F.S. CORREA. 1989. Potencial reprodutivo e longevidade de Chrysomya megacephala (Fabricius) (Diptera, Calliphoridae) em colônias sob condições de laboratório. Resumos do XII Congresso Brasileiro de Entomologia, Belo Horizonte, p.472.

Imbiriba, A.; D.T. IzUTANi; I.T. MiLhoreto \& E. LuZ. 1977. Introdução de Chrysomya chloropyga (Wiedemann, 1818) na região neotropical (Diptera, Calliphoridae). Arq. Biol. Tecnol., Curitiba, 20 (1-2): 35-39.

Linhares, A.X. 1981. Synanthropy of Calliphoridae and Sarcophagidae (Diptera) in the city of Campinas, São Paulo, Brazil. Revta bras. Ent. 25 (3): 189-215.

LomônaCO, C. \& A.P. PRADO. 1994. Estrutura comunitária e dinâmica da fauna de dípteros e seus inimigos naturais em granjas avícolas. An. Soc. Ent. Brasil 23 (1): 71-80.

Mendes, J. \& A.X. Linhares. 1993. Atratividade por iscas e estágios de desenvolvimento ovariano em várias espécies sinantrópicas de Calliphoridae (Diptera). Revta bras. Ent. 37 (1): 157-166.

NorRIS, K.R. 1965. The bionomics of bowflies. Ann. Rev. Ent. 10: 47-68.

PRADO, A.P. \& J.H. Guimarães. 1982. Estado atual de dispersão e distribuição do gênero Chrysomya Robineau-Desvoidy na região neotropical (Diptera, Calliphoridae). Revta bras. Ent. 26 (3/4): 225-231.

Quarterman, K.D.; W. Mathis \& J.W. Kilpatrick. 1954. Fly dispersal in a rural area near Savanah, Georgia. J. Econ. Ent. 47: 413-419. 
Veloso, V.R.S.; P.M. Fernandes; M.R. Rocha; M.V. Queiroz \& M.R. SILVA. 1994. Armadilha para monitoramento e controle das moscas-das-frutas Anastrepha spp. e Ceratitis capitata (Wied.). An. Soc. Entomol. Brasil 23 (3): $487-493$.

Recebido em 28.1X.1994; aceito em 27.IX.1995. 